\title{
Do AZT à PrEP e à PEP: aids, HIV, movimento LGBTI e jornalismo
}

From AZT to PrEP and PEP: AIDS, HIV, LGBTI movement and journalism

Del AZT a la PrEP y a la PEP: Sida, VIH, movimiento LGBTI y periodismo

\author{
Carlos Alberto Carvalho ${ }^{1, a}$ \\ carloscarvalho0209@gmail.com | http://orcid.org/oooo-0o01-8433-8794 \\ José Henrique Pires Azevêdo ${ }^{1, b}$ \\ jhpazevedo@gmail.com | http://orcid.org/oooo-ooo1-5489-241X \\ ${ }^{1}$ Universidade Federal de Minas Gerais. Belo Horizonte, MG, Brasil. \\ a Doutorado em Comunicação pela Universidade Federal de Minas Gerais. \\ b Mestrado em Comunicação Social pela Universidade Federal de Minas Gerais.
}

\section{Resumo}

O objetivo deste artigo é destacar características e atravessamentos dos movimentos LGBTI brasileiros, da aids, do HIV e de coberturas jornalísticas da síndrome que surgiu publicamente no início dos anos 1980. Resgatamos dimensões históricas e questões atuais como desafiadoras para as ciências, a medicina, governos e militantes com o intuito de refletir sobre disputas que estiveram e estão em curso, principalmente aquelas que se relacionam com a LGBTIfobia e outras opressões sociais. A pesquisa foi realizada por meio de levantamento bibliográfico acerca das políticas do movimento LGBTI, do HIV e da aids, bem como do uso de resultados de pesquisa anteriormente realizada sobre homofobia e narrativas jornalísticas. Observou-se uma conexão complexa entre as relações engendradas no surgimento da síndrome, próxima aos primeiros passos do movimento LGBTI no Brasil, como a produção ambivalente de visibilidades, assim como a manutenção de preconceitos históricos que ainda reverberam no tecido social.

Palavras-chave: Movimento LGBTI; HIV; Aids; Jornalismo; LGBTIfobia; Visibilidades. 


\section{Abstract}

The aim of this article is to highlight the characteristics and crossings of Brazilian LGBTI, AIDS, HIV movements and of journalistic coverage of the syndrome that emerged publicly in the early $1980 \mathrm{os}$. We brought up historical dimensions and current issues as challenging for the sciences, medicine, governments and militants in order to reflect on ongoing disputes, especially those that are related to LGBTIphobia and others social oppressions. The research was carried out through a bibliographical survey about policies of the LGBTI, HIV and AIDS movements, as well as the use of previously conducted research results on homophobia and journalistic narratives. It was observed a complex connection between the relations generated in the beginning of the syndrome, close to the first steps of the LGBTI movement in Brazil, as the ambivalent production of visibility, as well as the maintenance of historical prejudices that still reverberate in social world.

Keywords: LGBTI movement; HIV; AIDS; Journalism; LGBTIphobia; Visibility.

\section{Resumen}

El objetivo de este artículo es subrayar puntos y atravesamientos de los movimientos LGBTI brasileños, del Sida, del VIH y de las coberturas periodísticas del síndrome que surgió en público en el principio de los años 1980. Rescatamos dimensiones históricas y cuestiones actuales desafiantes para las ciencias, la medicina, los gobiernos y militantes con el propósito de reflexionar sobre disputas que estuvieron y están en curso, principalmente aquellas que se relacionan con la LGBTIfobia y otras opresiones sociales. La investigación fue realizada por medio de levantamiento bibliográfico acerca de las políticas del movimiento LGBTI, del VIH y del Sida, así como del uso de resultados de investigación previamente realizada sobre homofobia y narrativas periodísticas. Se observó una conexión compleja entre las relaciones engendradas en el surgimiento del síndrome, próxima a los primeros pasos del movimiento LGBTI en Brasil, como la producción ambivalente de visibilidades, así como el mantenimiento de prejuicios históricos que aún reverberan en el tejido social.

Palabras clave: Movimiento LGBTI; VIH; Sida; Periodismo; LGBTIfobia; Visibilidades.

Este texto compõe o dossiê $\mathbf{4 0}$ anos do movimento LGBT no Brasil: comunicação, saúde e direitos humanos.

Contribuição dos autores:

Concepção e desenho do estudo: Carlos Alberto de Carvalho e José Henrique Pires de Azevêdo.

Aquisição, análise ou interpretação dos dados: Carlos Alberto de Carvalho e José Henrique Pires de Azevêdo.

Redação do manuscrito: Carlos Alberto de Carvalho e José Henrique Pires de Azevêdo.

Revisão crítica do conteúdo intelectual: Carlos Alberto de Carvalho e José Henrique Pires de Azevêdo.

Declaração de conflito de interesses: não há.

Fontes de financiamento: Coordenação de Aperfeiçoamento de Pessoal de Nível Superior (Capes), Conselho Nacional de Desenvolvimento Científico e Tecnológico (CNPq) e Fundação de Amparo à Pesquisa do Estado de Minas Gerais (Fapemig).

Considerações éticas: não há.

Agradecimentos/Contribuições adicionais: não houve.

Histórico do artigo: submetido: 29 jan. 2018 | aceito: 24 maio 2019 | publicado: 28 jun. 2019.

Apresentação anterior: não houve.

Licença CC BY-NC atribuição não comercial. Com essa licença é permitido acessar, baixar (download), copiar, imprimir, compartilhar, reutilizar e distribuir os artigos, desde que para uso não comercial e com a citação da fonte, conferindo os devidos créditos de autoria e menção à Reciis. Nesses casos, nenhuma permissão é necessária por parte dos autores ou dos editores. 
"Veados americanos trazem o vírus da AIDS

Para o Rio no carnaval

Veados organizados de São Francisco conseguem

Controlar a propagação do mal

Só um genocida potencial

- de batina, de gravata ou de avental -

Pode fingir que não vê que os veados

- tendo sido o grupo-vítima preferencial -

Estão na situação de liderar o movimento

Para deter a disseminação do HIV"

Caetano Veloso ${ }^{1}$

\section{Introdução}

O trecho da música Black or White/Americanos, composta e gravada por Caetano Veloso no disco Circuladô Vivo (1992), é uma mistura de cover de Michael Jackson que tomamos como epígrafe para este artigo, por oferecer pistas históricas preciosas para o objetivo deste estudo. Interessa-nos indicar algumas características dos movimentos LGBTI (Lésbicas, Gays, Bissexuais, Transsexuais, Travestis e Interssexuais) e de sua relação com as coberturas jornalísticas das campanhas nacionais de aids (Síndrome da Imunodeficiência Adquirida) e de HIV (Vírus da Imunodeficiência Humana), síndrome que assombrou a humanidade no início dos anos 1980 e continua, como realidade complexa, a desafiar as ciências, a medicina, os governos e os militantes pelos direitos humanos e por tratamentos de saúde com acesso universal.

Do ponto de vista histórico, a letra de Caetano Veloso reflete convicções científicas que se provaram equivocadas, sendo a dos homossexuais masculinos como grupo preferencial, 'de risco', a mais danosa e ainda hoje difundida. Na música aparecem crenças não necessariamente fundadas em dados reais, mas certamente calcadas em estereótipos, como a de que "veados americanos" traziam a aids para o Brasil durante o carnaval, e pistas a seguir - como a militância dos "veados de São Francisco" e a existência de "genocida em potencial" - "de batina, de gravata ou de avental" - alusão a conservadores das áreas de religião, política e saúde que impuseram dificuldades ao combate à disseminação do HIV e ao tratamento das consequências médico-sociais da aids em seus primeiros momentos, com atuações retrógradas ainda hoje. Faltaram referências às mídias - também importantes atrizes da equação naqueles primeiros anos - sejam as informativas, sejam as de entretenimento, em papéis ambíguos alternando entre espraiamento do terror e da desinformação ou informação equivocada e divulgando formas de prevenção, nas duas condições, mas particularmente na primeira, com alto teor de homofobia.

Mas não estamos diante do propósito de fazer uma crítica musical, ou de indicar erros e acertos históricos contidos na letra da música, e sim, entendermos como é possível estabelecer algumas relações entre militância LGBTI (portanto, mais ampla do que a dos "veados de São Francisco" poeticamente referidos por Caetano Veloso'), e a síndrome de aids/HIV, tomando como referência a realidade brasileira, e, em movimento paralelo, identificar algumas características de coberturas jornalísticas sobre aids e HIV desde o surgimento dessas realidades nos campos da saúde pública e das relações sociais. Faremos apontamentos que intercalam dimensões históricas específicas, alguns traços dos movimentos de militância LGBTI no Brasil e dados sobre coberturas jornalísticas que tiveram a aids e o HIV como acontecimentos, nesse caso, também indicando como a homofobia tende a ser realidade recorrente quando a síndrome está associada às pessoas LGBTI, particularmente homossexuais masculinos, desde os primeiros casos registrados, com a incorporação, na sequência, de travestis e transexuais.

Embora o título do artigo possa sugerir progressos lineares no tratamento e prevenção da aids e do HIV, do pioneiro uso do AZT, detonador de diversos e sofridos efeitos colaterais, às possibilidades atuais de utilização de medicação pré e pós exposição ao vírus, não adotamos tal equívoco. Primeiro, porque a solução sonhada, a vacina, tem sido batalha por enquanto perdida, a despeito dos gigantescos investimentos 
de pesquisa e recursos humanos e financeiros. Acrescente-se que, do ponto de vista da eficácia, os coquetéis apresentam resultados satisfatórios, tornando indetectável a carga viral do HIV, mas podem gerar efeitos colaterais desagradáveis e mesmo incompatibilidade orgânica para algumas pessoas. Os altos custos dos medicamentos constituem outra ordem de desafios, pairando sempre a incerteza política sobre a continuidade, no Brasil, de garantia de tratamento gratuito e universal, conquista de poucos países no mundo. No caso do uso da medicação pré e pós exposição ao HIV, as discussões são ainda mais acirradas, com recuos governamentais quanto à garantia de distribuição gratuita nas situações indicadas, debate permanentemente sob ameaça de interdição por parte de grupos conservadores. Pois estão concentradas exatamente nas articulações de tais grupos as maiores ameaças às políticas públicas de tratamento e prevenção da aids e do HIV, pelas posturas culturais e comportamentais guiadas por fundamentalismos de diversos matizes, especialmente religiosos. Mas não só, como nos lembra Caetano Veloso, pela trupe de genocidas potenciais, "de batina, de gravata ou de avental".

Se do ponto de vista dos avanços médicos e científicos não é possível pensar em progressos lineares, menos ainda são viáveis tais perspectivas quando nos defrontamos com as realidades políticas, culturais e comportamentais. Embora sejam detectáveis mudanças de mentalidade nessas esferas da vida social brasileira, na direção de maior acolhimento da diversidade de gênero e no reconhecimento ao menos de que as pessoas LGBTI têm direito a reivindicarem direitos, a realidade é de cenários de lentos avanços e de retrocessos em ritmo mais acelerado. Os resultados das eleições de 2018 para os poderes executivos e legislativos estaduais e federais são, nesse sentido, reveladores. Ainda que com a eleição ou reeleição de parlamentares identificados com as causas e as pessoas LGBTI, o cenário é de aumento de bancadas conservadoras, particularmente as comprometidas com fundamentalismos religiosos de diversos matizes. E na presidência da República, um ocupante ostensiva e reiteradamente hostil às causas e às pessoas LGBTI. Encerra-se, assim, um ciclo de ações governamentais que, embora tímidas, na última década e meia foram marcadas pela implementação de políticas específicas para a população LGBTI².

Metodologicamente, adotamos dois movimentos complementares na escrita deste artigo. O primeiro, a leitura e revisão crítica de artigos e livros que tratam das dimensões históricas e sociais da aids e do HIV, tanto aqueles cujas abordagens estão mais centradas em questões médicas e científicas, quanto os mais preocupados com questões sociais, culturais, políticas e comportamentais. Nesse percurso histórico incluímos textos diversos que analisam os processos de divulgação jornalísticos, publicitários e institucionais (promovidos por governos, ONGs, entre outros agentes). Recorremos ainda a literaturas que abordam aspectos históricos dos movimentos LGBTI brasileiros, inclusive aquelas que estabelecem correlações e impactos do surgimento da aids e do HIV sobre as estratégias de militância política. O segundo movimento consistiu em recorrer a pesquisas por nós já realizadas nos últimos anos, nas quais trabalhamos com coberturas jornalísticas de acontecimentos relativos à aids e ao HIV e como tais notícias revelam dimensões de homofobia.

\section{Notas sobre movimentos LGBTI...}

A organização política de movimentos sociais ligados aos grupos LGBTI no Brasil, no primeiro momento chamado de 'movimento homossexual', ganhou maior expressão no final da década de 1970, contexto de intensa efervescência cultural e de luta contra a ditadura civil-militar ${ }^{2-4}$. O primeiro coletivo organizado, o Grupo Somos, fundado em 1978 em São Paulo, é característico de um período de fortalecimento das políticas identitárias que vinham ganhando forma ao redor do mundo, como por exemplo os movimentos negros e feministas 5 . Nesse período, outras iniciativas foram sendo construídas em torno da emancipação das pessoas LGBTI, tendo como principais bandeiras o reconhecimento de seus direitos civis e a proposição de visibilidades para esses sujeitos. Naquele contexto surge o jornal 'Lampião da Esquina', uma das 
primeiras publicações brasileiras voltadas para a população homossexual, outra vez em sintonia com o que vinha ocorrendo em partes da Europa e nos Estados Unidos, não por mero acaso, mas como resultado das experiências de muitos militantes exilados que viveram nesse último e em países do continente europeu. Experiências de militância LGBTI na América Latina, como as argentinas e mexicanas, também são consideradas por algumas pessoas como influências importantes para ativistas do Brasil².

Se, por um lado, experiências de movimentos de direitos civis para pessoas LGBTI estrangeiras influenciaram, ou serviram de estímulo para seus congêneres brasileiros, por outro, as estratégias de luta política não foram simplesmente transpostas, entre outras razões, pelas condições impostas por uma ditadura civil-militar ainda repressiva, a despeito da progressiva abertura política, que teve na anistia um dos seus principais marcos. Nessa perspectiva, como lembra Regina Facchini ${ }^{6}$, é importante destacar que o governo ditatorial tem nas variadas resistências a ele motivos para desgaste, não sendo prudente considerar que, somente após o processo de abertura, ações políticas de pessoas e grupos como os LGBTI tenham se tornado possíveis. Antes, ações dessa natureza foram parte do desgaste dos governos repressivos e opressores, contribuindo para a inviabilidade de que continuassem à frente do Estado brasileiro.

Mas é também fundamental considerar, na esteira de João Silvério Trevisan ${ }^{3}$, que as motivações políticas não foram as únicas propulsoras dos primeiros grupos homossexuais organizados brasileiros. Ou, por outro lado, que é necessário entender que ao lado da luta política em suas modalidades tradicionais, se encontravam também reivindicações e ações identificadas com políticas do prazer, da estética, da ajuda mútua e da liberdade de ser o que se quisesse. João Silvério Trevisan, aliás, indica não somente sua resistência pessoal, como de outras pessoas responsáveis pela criação do Somos, em relação às formas tradicionais de luta política, que poderiam levar os coletivos a ficarem subordinados a lógicas e estruturas partidárias. Nesse sentido, tanto a esquerda quanto a direita sempre foram refratárias às questões caras às pessoas LGBTI, com tradição, na esquerda brasileira, de considerar que o que hoje denominamos reivindicações de gênero constituíam, além de proposições burguesas, táticas que desviavam os rumos da revolução proletária.

Embora a resistência aos modelos convencionais de militância política não tenha sido unanimidade entre as primeiras pessoas envolvidas com as causas das populações LGBTI, ela é um importante indicador da ausência de unidade programática nos primórdios do movimento no Brasil. Mas não consistiu na única marca de dificuldade unitária, motivo pelo qual, inclusive, alternamos neste artigo entre referências a movimentos homossexuais e movimentos LGBTI, os últimos certamente denominação mais apropriada para os anos 2000, e indicando muito mais diversidade de interesses e reivindicações do que unidade em torno de uma sigla que, no título do livro de Regina Facchini ${ }^{6}$, recebe a precisa denominação de 'sopa de letrinhas'. Sopa temperada segundo paladares distintos, com ingredientes também diversos e certamente conflituosa, com momentos indigestos em que, por exemplo, lésbicas denunciavam a pouca importância que os gays lhes dedicavam na construção dos movimentos e pessoas negras alertavam para as suas especificidades na luta contra os preconceitos raciais e de gênero ${ }^{2}$.

No fundo, a metáfora da sopa de letrinhas é reveladora, em perspectiva histórica, da dificuldade inicial dos movimentos LGBTI brasileiros de ações interseccionais mais efetivas, que dessem conta de abarcar conjuntamente as dimensões de gênero, de classe e raciais como determinantes para o estabelecimento de políticas mais amplas e mais plurais, que reconhecessem os distintos níveis de enfrentamento das dificuldades impostas pela condição de ser LGBTI em contextos sociais, econômicos, geográficos, culturais e étnicos distintos. Sintomáticas dessa dificuldade são as composições dos coletivos pioneiros em ambientes predominantemente urbanos, notadamente as maiores capitais de estados brasileiros, e formados por maioria de homens brancos de classe média. Mas ainda resta uma importante lacuna em estudos históricos, sociológicos, antropológicos e de outras áreas de conhecimento que deem conta dessas dimensões de interseccionalidade no interior dos movimentos LGBTI no Brasil, ainda que algumas iniciativas já venham sendo empreendidas nessa direção ${ }^{2}$. 
Ainda nos marcos da metáfora da sopa de letrinhas, não foi por acaso que passamos da sigla GLBT (gays, lésbicas, bissexuais e travestis), para LGBT (lésbicas, gays, bissexuais e travestis), decisão de natureza política que atendeu a reivindicações das lésbicas de combate à invisibilidade a que estão historicamente submetidas. A denominação LGBTI, aqui adotada, incorpora novas pessoas, significando lésbicas, gays, bissexuais, travestis, transexuais e interssexuais, mas a ela tem sido acrescido o ‘+', com o objetivo de indicar outras expressões da sexualidade e do desejo, indicando o quão complexas são as identidades e as relações de gênero, inclusive pelo fato de não envolverem, para algumas pessoas, práticas sexuais. A constante mudança da sigla, se por um lado evidencia dificuldades de se encontrar consenso no universo LGBTI, por outro, indica a ampliação do escopo das associações específicas criadas por travestis e transexuais, por exemplo. Assim, o que em um primeiro momento pode ser lido como fragmentação, revela-se como a ampliação de reivindicações de direitos que levem em conta vivências, experiências, necessidades e políticas específicas, dando ainda a ver a busca por espaços de poder a partir das próprias ações das pessoas diretamente implicadas, e não por representação de terceiros.

Como resultado, somados aos pioneiros movimentos homossexuais do final da década de 1970, temos visto surgir no Brasil do século XXI movimentos que incorporam a sopa de letrinhas LGBTI, não necessariamente juntas e misturadas em uma mesma sopeira. Em parte, como discutimos na sequência, essa ampliação da militância mantém relações com a necessidade de enfrentamento das consequências médicas e sociais da aids e do HIV. Importante também registrar que parcela do que denominamos movimentos LGBTI passa a ser constituída por Organizações não Governamentais (ONGs), com todos os problemas e soluções daí advindos, conforme análise de Regina Facchini ${ }^{6}$.

O destaque dado aos movimentos LGBTI coletivos, desde os pioneiros movimentos homossexuais, além dos possíveis equívocos acerca de supostas unidades programáticas que indicamos, traz ainda o risco de apagar contribuições individuais decisivas, nas décadas de 1970 e de 1980, para a constituição dos contornos políticos das lutas das pessoas identificadas com a sopa de letrinhas. Nesse sentido, Herbert Daniel é uma figura emblemática, pois uniu militância política tradicional contra a ditadura civil-militar, militância em torno das homossexualidades e envolvimento com as políticas de tratamento e prevenção da aids e do HIV .

Foi ainda, mesmo sem o reivindicar, um teórico sobre as (homo)sexualidades com reflexões complexas e refinadas, abordando temas que hoje identificamos como corpos que pesam e por que pesam, falácias do binarismo e da biologização sexual, denúncia da imposição da heteronormatividade, perigos e armadilhas da noção de 'minorias', riscos da reivindicação de um estatuto do 'homossexual' como categoria de qualquer matiz que fosse, indicação dos preconceitos contra pessoas negras e mulheres etc. Embora com a utilização de conceitos, termos e palavras distintos dos que utilizamos atualmente, os problemas teóricos por ele abordados são as recorrências nossas e das bibliografias das quais nos valemos, formuladas segundo o disponível nos anos 1980. A leitura do livro Jacarés e lobisomens: dois ensaios sobre a homossexualidade7, obra em parceria com Leila Míccolis, é referência indispensável se quisermos entender como historicamente as questões relativas às pessoas LGBTI têm sido abordadas no Brasil, assim como outras publicações, nas quais há relevo também para as dimensões médicas, culturais e sociais da aids e do HIV ${ }^{9,10}$.

\section{...E de respostas à aids}

O que nos anos 2000 viria a se transformar no movimento LGBTI ainda estava em seu início no Brasil quando, em princípios da década de 1980, começaram a aparecer os primeiros casos de adoecimento em decorrência da aids, que foi logo anunciada por jornais ao redor do mundo como 'peste gay', 'câncer rosa' ou, na linguagem científica, Gay-Related Immune Deficiency (Imunodeficiência relacionada a gays, em tradução livre). Os equívocos clínicos e epidemiológicos das ciências médicas, assim como a atuação das mídias informativas, promoveram uma associação do vírus com as homossexualidades, que se manteve 
nos entendimentos sobre a epidemia, fomentando a homofobia e alimentando o preconceito sobre o vírus

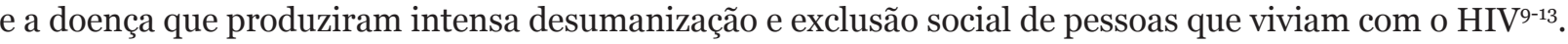

Com a expansão da aids e dos seus sentidos, a homofobia já existente no tecido social recrudesceu, agora cientificamente legitimada, e a parcela conservadora da população podia comemorar o que Eve Kosofsky Sedgwick chamou de possível realização de um sonhado "holocausto gay" ${ }^{\text {", }}$ cuja consecução fora iniciada nos campos de concentração nazistas. A expressão da autora chama atenção não só para a sistemática perda de vidas de homens gays, quanto para um grau de negligência diante dessas perdas, em ações que Achille Mbembe denomina "necropolítica"15, no contexto da desvalorização da vida de pessoas negras e de outras cujas existências são sistematicamente negadas e boicotadas a partir de lógicas racistas, sexistas, xenófobas e de outras modalidades de exclusão que conduzem, não raro, a extermínios em massa ou individuais. No governo de Ronald Reagan nos Estados Unidos, onde os primeiros casos foram notificados, a epidemia foi ignorada, o que ocorreu de modo semelhante no Brasil, em que a aids não foi encarada em seus anos de surgimento como um problema de saúde pública ${ }^{16}$.

Após um curto período, a partir do final dos anos 1960, em que parecia possível realizar a utopia do amor livre, aí incluídas as vivências LGBTI, o mundo se depara com o horror da aids e do HIV, tornados públicos precisamente na década em que retrocessos conservadores nos campos políticos, econômicos, culturais e comportamentais eram capitaneados pelo presidente dos Estados Unidos, Ronald Reagan, pela primeiraministra britânica, Margareth Thatcher, e pelo papa João Paulo II. Mas se a aids e o HIV impuseram, na primeira década da sua expansão, milhares de mortes, tanto físicas quanto simbólicas, impondo perdas de pessoas famosas e anônimas de diversas áreas de atuação, eles também chamaram atenção para a necessidade de novas plataformas e estratégias de ações políticas, particularmente para pessoas LGBTI.

Diante da negligência do aparato estatal, da dimensão e imprevisibilidade da epidemia e das imprecisões médico-científicas, coube à sociedade civil se organizar para dar uma resposta à aids, que veio em grande parte dos emergentes movimentos homossexuais. Esses grupos foram essenciais na configuração de um enfrentamento à expansão da aids tanto no que diz respeito ao adoecimento e à perda de inúmeras vidas quanto da contenção de toda repercussão discursiva, social, política e cultural que estava em curso ${ }^{16,17}$. E, se por um lado esses grupos ajudaram a construir uma agenda de resposta à epidemia no Brasil, por outro, o próprio movimento LGBTI foi se estruturando e se fortalecendo nessa luta, fenômeno muitas vezes analisado como 'repercussão positiva' do surgimento da aids e do HIV ${ }^{18,19}$.

A efetiva atuação dos movimentos homossexuais, no início dos anos 1980, ampliados para movimentos LGBTI no século XXI, na elaboração de estratégias de prevenção e tratamento da aids e do HIV deve ser entendida a partir da inevitável ambiguidade derivada da visibilidade que esses movimentos adquiriram². Tal como na música de Caetano Veloso, se os "veados de São Francisco"' foram 'grupos preferenciais', seria inevitável que partissem deles, aqui tomados como homossexuais espalhados pelo mundo todo, assim como de outras populações da sopa de letrinhas, iniciativas políticas de enfrentamento de preconceitos, de reivindicação de direitos e de denúncia da inércia de governos diante da urgência do estabelecimento de políticas de saúde e sociais.

Embora inegavelmente tenham sido os homossexuais masculinos pioneiros nas lutas envolvendo os múltiplos desafios impostos pela aids e pelo HIV, contribuindo, no caso brasileiro, para reavivar os movimentos homossexuais, inclusive com a ampliação do seu escopo de reivindicações e de ações, o aspecto negativo ficou por conta do reforço, em alguns estratos sociais, de 'incidência exclusiva' da aids e do HIV. Muitos estudiosos indicam ainda, como aspecto negativo dessa dinâmica, a patologização, ou repatologização das homossexualidades, recentemente retirada do catálogo de doença quando do surgimento da aids e do HIV $^{20}$. A nova dimensão patológica não significava o retrocesso à homossexualidade em si como doença, mas o potencial caráter 'adoençável' dos corpos homossexuais, aqui se expandindo para a população constituinte da sopa de letrinhas. Importante destacar que, para Herbert Daniel, a compreensão dos 
modos como a aids e o HIV se espalharam não pode se restringir à constatação de incidência privilegiada sobre homossexuais masculinos e ao recrudescimento dos preconceitos, pois há componentes de classe, por exemplo, que também devem ser considerados. Mais relevante ainda, fica patente a necessidade de desconstruir discursos médicos e científicos, além de outros, para impedir que da condição de patologia, a aids e o HIV transformem a homossexualidade em condição patogênica. Como bem indica Herbert Daniel, o vírus não tem ideologia, religião ou qualquer critério seletivo9.

O maior desafio enfrentado pelos movimentos LGBTI frente à aids e ao HIV certamente recai sobre os corpos, aqui tomados como metáfora que inclui a reivindicação de reconhecimento da alteridade, a luta contra o controle biomédico e biopolítico das expressões das sexualidades, dos desejos e dos prazeres e pelo reconhecimento da diversidade de gênero e sua aceitação, sem tergiversações de qualquer ordem ou adversativos quaisquer que sejam. Luta que inclui em sua linha de frente o direito ao 'corpo soropositivo' de circular livremente, sem quaisquer modalidades de controles médicos ou morais, deixando para trás as tentativas, de triste memória, de confinamento dos então preconceituosamente designados 'aidéticos'.

Metáforas potentes, assim como matéria física resistente, os corpos LGBTI têm se multiplicado nas frentes de ação contra todas as formas de injúrias, exclusões, preconceitos e hierarquizações, levando adiante a perspectiva de viver com o HIV, e não de morrer em decorrência da aids. A partir desse mote, tornou-se fundamental separar aids e HIV, exercício epistemológico e político que traz, para o primeiro plano, a luta pela continuidade e ampliação de políticas públicas de tratamento e prevenção universais, a incorporação de todos os avanços médicos e científicos acima de interesses comerciais e financeiros e atitudes cada vez mais crescentes de não ocultar a sorologia positiva para HIV, entendendo a publicização como estratégia política em todas as suas possíveis dimensões. Nesse escopo de ações, está em pauta a recusa de que as ciências médicas, psicológicas e outras, assim como governos, religiões e quaisquer outras instituições determinem unilateralmente os sentidos da aids e do HIV. E, por extensão, a inequívoca indicação de liberdade para todos os corpos das pessoas LGBTI, independentemente de sorologia positiva para o HIV ou quaisquer outras condições físicas e sociais.

No Brasil, como indicam diversas pesquisas ${ }^{2,20}$, a ampliação do espectro político e de pessoas LGBTI criando associações e ONGs mantém íntima relação com as lutas e reivindicações em torno da aids e do HIV. Em que pesem críticas como a possível tutela governamental e a criação de entidades mais focadas nas disputas pelos parcos recursos financeiros vindos de programas oficiais para combate ao HIV e tratamento da aids, é necessário reconhecer que ações como as promovidas pelo Ministério da Saúde foram fundamentais para a criação, ampliação e fortalecimento de associações de travestis e transexuais, para ficarmos em dois exemplos. O tom ácido de algumas críticas pode esconder transfobia não admitida e conter a noção de que travestis e transexuais seriam pouco capazes de proporem pautas de reivindicações que contemplem suas especificidades e dilemas, que envolvem, quase sempre de forma contundente, administrar o próprio corpo.

Nesse sentido, a noção do corpo é ainda mais potente para essas pessoas e não se trata somente das dimensões já indicadas no que se refere à aids e ao HIV, mas de desafios mais complexos. Estão em jogo políticas públicas de saúde que envolvem tratamentos hormonais, aplicações de silicone, cirurgias de redesignação de gênero, sensibilização de agentes de saúde para abordagens não preconceituosas, entre um leque variado de desafios cotidianamente ameaçando solapar a existência física e simbólica de travestis e transexuais. A batalha pela dignidade inclui os árduos desafios políticos e legais pelo direito a nome social e mesmo para a mudança de nome ${ }^{2}$. Certamente, frentes de ação que não podem ser delegadas às demais componentes da sopa de letrinhas, mas que devem contar com a irrestrita solidariedade e luta conjunta da sopeira. 


\section{PrEP, PEP e novos desafios aos movimentos IGBTI}

Os avanços técnicos e farmacêuticos dos últimos anos possibilitaram a manipulação de uma série de ferramentas de tratamento e prevenção ao HIV que, ao serem incorporadas às estratégias de resposta à epidemia, expuseram um conjunto de conflitos e contradições relativas não só ao vírus, como aos corpos por ele alcançados seja física ou virtualmente pelo espectro das associações preconceituosas. Exemplar nesse sentido é o uso da PrEP, Profilaxia Pré-Exposição, método de prevenção ao HIV que consiste na ingestão diária de um comprimido capaz de impedir que o vírus invada as células de defesa do organismo. Conhecido popularmente como Truvada, o antirretroviral passou a ser distribuído gratuitamente pelo Ministério da Saúde no Brasil, em 2017, para as consideradas populações-chave ou para as pessoas mais vulneráveis ao HIV segundo o órgão federal, entre elas os HSH (homens que fazem sexo com homens), pessoas trans e trabalhadoras(es) do sexo. Ainda como parte das políticas de prevenção e controle da disseminação do HIV, o Ministério da Saúde mantém a PEP, Profilaxia Pós-Exposição de Risco, que consiste no uso de medicamentos antirretrovirais para reduzir o risco de infecção em situações de exposição ao vírus. A profilaxia é recomendada em casos de violência sexual, relação sexual desprotegida (sem uso ou com ruptura da camisinha) e acidente ocupacional que resulte no contato com material biológico, com tratamento de urgência, segundo o Ministério da Saúde, preferencialmente iniciado duas horas após o evento de risco, com 72 horas máximas de tempo decorrido, e uso de medicação durante 28 dias.

Desde 2004, nos Estados Unidos as primeiras pessoas, incluindo voluntários, que começaram a utilizar a PrEP foram chamadas de Truvada whore, algo como 'puta da Truvada'. A expressão pejorativa, destinada especialmente para homens gays, revela a associação do então novo método preventivo com identidades sexuais, reavivando preconceitos históricos, como da associação da homossexualidade com a promiscuidade. De forma semelhante, em 2018, a revista Época ${ }^{21}$ lançou uma edição com a capa "A outra pílula azul: o novo medicamento que está fazendo os gays abandonar a segurança da camisinha”. O repórter que narra sua visita a uma casa noturna frequentada pelo público LGBTI em São Paulo, um lugar 'propositalmente lúgubre', dá detalhes das relações sexuais ocorridas ali e contabiliza não só o número de parceiros sexuais de um sujeito, como a quantidade de camisinhas jogadas ao chão no final da noite. Além da descrição moralista e estereotipada, a reportagem sugere que nesses ambientes há uma falta de cuidado na prevenção sexual e indica que essa seria a falha da resposta brasileira na contenção do aumento nos números de infecções pelo HIV no país.

Em resposta à revista, o Ministério da Saúde fez uma carta de repúdio, reafirmando o lugar da PrEP nas estratégias de prevenção combinada traçadas pelo órgão e rechaçando a reprodução de preconceitos como a associação do HIV à população LGBTI, em que seus membros são indicados como irresponsáveis por, supostamente, terem deixado de lado a camisinha nas relações sexuais. Nesse mesmo sentido, o infectologista Rico Vasconcelos, que havia sido entrevistado pela reportagem, manifestou publicamente seu arrependimento e afirmou que o texto, além de preconceituoso, fazia um desserviço na divulgação de informações sobre um serviço de saúde importante e que ainda estava nos primeiros meses de implementação no país.

A responsabilização de homens gays pelo aumento do número de novas infecções ou pelo abandono do uso da camisinha, como aparece na revista, encontra brechas em outros lugares e reproduz premissas moralistas e discriminatórias, como a ideia de que jovens gays brasileiros têm se infectado mais por utilizarem aplicativos de relacionamento que supostamente facilitam o maior número de relações sexuais ou ainda que, por serem novos, desconhecem os anos de horror vividos pelas gerações que presenciaram o início da epidemia da aids. A lógica por trás do argumento de que esses jovens são descuidados e promíscuos, assim como a reivindicação de uma pedagogia do medo pela ótica da falta de memória nos parecem insuficientes para responder à epidemia e podem aumentar ainda mais as barreiras para a construção de estratégias mais eficientes para diminuir o número de novas infecções e garantir qualidade de vida e o bem-estar para quem vive e convive com o HIV. 
Tais argumentos são incapazes de trazer à tona variáveis outras que possam ajudar a entender o quadro atual da aids e do HIV no Brasil, ou mesmo pensar em suas dinâmicas específicas para a população LGBTI. A manutenção dos índices mais acentuados de novas infecções entre as pessoas trans, por exemplo, não é reflexo de suas identidades sexuais e de gênero como pode ser muitas vezes sugerido, mas de um conjunto sistemático e estruturante de violências cometidas contra esses sujeitos, inclusive pelo próprio Estado, que se desresponsabiliza pelo cuidado e proteção dessas vidas ${ }^{22}$. Desse modo, as argumentações moralistas e preconceituosas que obliteram, como a homofobia e a transfobia, por exemplo, são constituintes das dinâmicas de transmissão e tratamento do HIV atualmente. Ao lado da nova realidade política brasileira a que aludimos anteriormente, eis uma panorâmica do cenário que desafia os movimentos LGBTI em suas estratégias políticas e de enfrentamento de uma miríade de questões extremamente complexas, entre as quais as relativas à aids e ao HIV constituem, recorrendo a um clichê, apenas a ponta do iceberg.

Os sentidos da militância LGBTI certamente têm se ampliado, com a incorporação de novas estratégias de ação e novas atrizes e novos atores, convivendo com antigas entidades, coletivos e ONGs. Particularmente importantes são as atuações a partir da internet, com blogs e canais no YouTube, como o Canal das Bee, Para Tudo, Mandy Candy e Louie Ponto, que promovem visibilidade para vivências e experiências LGBTI que priorizam o protagonismo na fala sobre si e buscam constituir uma alternativa à falta de narrativas, o que é conhecido e frequentemente lembrado nos debates do movimento como ausência de representatividade, ou à circulação de narrativas equivocadas a respeito desses sujeitos que compõem a sopa de letrinhas.

Nessa mesma linha, com o propósito de publicizar as questões relativas ao HIV, à aids e a aspectos da sexualidade, canais do YouTube como o Boa Sorte, HDiário e Super Indetectável emergem como promotores de visibilidade para pessoas que, após descobrirem a sorologia positiva para o HIV, encontram nas plataformas digitais espaços em que essas condições podem ser publicizadas e politizadas, operando na constituição de novos sentidos para o vírus e para esses corpos em um movimento constante de distanciamento de preconceitos arraigados e questionamento de pressupostos morais e estereotipados, como sinalizados anteriormente. Nesses espaços compartilham-se experiências sobre os processos de testagem, de diagnóstico, de tratamento e, principalmente, evidencia-se um conjunto de relações culturais, afetivas, comportamentais e éticas envolvidas no viver e conviver com o HIV, expressão recorrentemente utilizada, que rompe com os vestígios de fatalidade outrora correlacionados à aids e chama atenção para a potência de vida 'apesar de' e ‘com' o vírus.

É importante, ainda, registrar a exposição pública da sorologia positiva para o HIV como decisão pessoal, e não como consequência da 'arrancada do armário' que os corpos atingidos pela aids em seus primórdios se viam arrastados e violentados. A exposição deliberada em um contexto de cronicidade e garantia de qualidade de vida com HIV é estratégica, se alicerça em uma visibilidade motivada pelo orgulho de ser quem se é e pela busca por reconhecimento social e de direitos para quem vive e convive com o HIV, negando a redução desses corpos à semântica do perigo, do contágio ou do vetor de transmissão. Enfrentando um espectro social e imagético denso e desumanizador como o da aids, uma doença sempre associada ao outro, a aparição pública desses sujeitos a partir de seus cotidianos e nas suas reivindicações políticas evidencia um processo de positivação dessas experiências, para usar um trocadilho, no intento de produzir outros processos de subjetivação que não sejam marcados pelo isolamento social e pela injúria, assim como estabelecer espaços de circulação de informações que podem ser úteis na gestão da vida e promoção de saúde e bem-estar em uma dimensão holística do cuidado do corpo, das relações sociais etc.

Essas ações revelam nuances que não são as mesmas, porém lembram aspectos de iniciativas de resposta à aids que se basearam na promoção de saúde e cuidado para além das dimensões fisiológicas, oferecendo apoio emocional e criando espaços seguros em que pudessem ser elaboradas e compartilhadas experiências de pessoas que viviam e conviviam com o HIV, além da articulação em torno de uma agenda política mais institucionalizada para resposta à aids. Em que pese a diferença dos contextos de luta por sobrevivência e 
construção paulatina de um aparato de política de saúde pública em um momento de pânico e exclusão moral, esses sentidos e formas mais atuais de militância mostram como ainda é necessária a atenção cuidadosa à gestão da vida com qualidade após o diagnóstico do HIV, o monitoramento e avaliação constante do funcionamento dos modelos de tratamento e prevenção e, tal qual na década de 1980, o enfrentamento de preconceitos que insistem em criar hierarquizações e marginalização de corpos considerados socialmente indesejáveis pelos genocidas "de batina, de gravata ou de avental", assim como também por um exército de genocidas que não usam uniforme.

\section{Notas sobre coberturas jornalísticas relativas à Aids e ao HIV}

Se as mídias jornalísticas são inegavelmente fonte privilegiada para nos informarmos sobre os acontecimentos do mundo, são na mesma proporção controversas quanto às suas capacidades de fornecer informações eticamente comprometidas com dados factuais e isentas de preconceitos de diversas ordens, particularmente quando diante de temáticas como as trabalhadas neste artigo. Complexas em suas condições de produção, as narrativas jornalísticas resultam de um leque de agentes, entre os quais quem se ouve para a compreensão do acontecimento em pauta, o que pode induzir a erros, voluntários ou não, na disseminação de informações, como a crença médico-científica inicial dos 'grupos de risco'. Fruto do que até então estava sistematizado por uma atônita comunidade médica, a noção de incidência privilegiada não foi uma criação jornalística, mas certamente deveu ao jornalismo parte da sua difusão, com o acento homofóbico - especialmente da imprensa sensacionalista, mas não só - com a adoção, em manchetes escandalosas, das expressões 'câncer gay', 'peste rosa' e assemelhadas.

Logo que a aids ganhou dimensão pública no Brasil, a cobertura do jornal Folha de S.Paulo, entre 1983 e 1987, foi num crescente aumento dos casos relatados, espécie de 'corrida de cavalos' em que o Brasil disputaria posições entre os países com maiores registros de casos, tanto de mortes, quanto de soropositivos. Chama atenção que a Folha preconiza, em editorial, tratar a aids como doença social, o que a pautaria segundo preceitos éticos que deveriam evitar preconceitos e outras estratégias de marginalização. Com cobertura focada mais em questões comportamentais e culturais do que nas dimensões médicas e científicas, o jornal teve em grupos de militância no entorno da aids e do HIV, com suas consequências, fontes privilegiadas, com destaque para o Gapa-SP. Embora homofobia não fosse palavra utilizada naquela época, seus sentidos podem ser apreendidos em uma diversidade de narrativas, que abordavam, ainda, impactos sobre travestis e prostitutas ${ }^{23}$.

Passadas quase três décadas do surgimento da aids e do HIV, a leitura de jornais continuava sugerindo noções de homossexuais masculinos como 'grupos de risco', indicando a persistência social de um equívoco histórico, mas, sobretudo, da homofobia como organizadora de exclusões e de práticas de violências físicas e simbólicas ${ }^{19}$. Em pesquisas realizadas na década de 2010, com recorte nos jornais Estado de Minas, Folha de S.Paulo e O Globo, percebemos fortes resquícios culturais do início dos anos 1980 nas correlações entre aids, HIV e homossexualidade, particularmente a masculina. Não é possível, no entanto, encontrar posturas idênticas nas três publicações no que se refere às correlações entre homofobia, aids e HIV. Por exemplo, no Estado de Minas e em O Globo há narrativas jornalísticas conforme a pedagogia do terror, na linha de raciocínio da matéria da revista Época anteriormente referida. No Estado de Minas, uma narrativa retoma literalmente os termos 'agonizar em praça pública', utilizados pela revista Veja em capa sobre Cazuza - considerada uma das ações mais antiéticas e nefastas da imprensa brasileira - para referirse ao aumento de soropositivos entre jovens gays que se contaminariam por não terem vivido os horrores dos anos iniciais da síndrome. Também em O Globo encontramos narrativas relacionando aumento de casos de HIV em jovens gays e não vivência dos anos 1980, trazendo depoimentos de jovens homossexuais e textos de tom conservador e moralista ${ }^{24,25}$. 
Nos jornais Folha de S.Paulo e O Globo a homofobia não raro é indicada como componente decisivo para o aumento da vulnerabilidade à exposição ao HIV, assim como para maiores possibilidades de morte em decorrência da aids. Os dois jornais se posicionam editorialmente favoráveis à criminalização da homofobia, embora a Folha adote a questionável argumentação de que uma lei nessa direção traria em si o risco de ferir o direito à expressão de opiniões, particularmente as religiosas. Já o Estado de Minas passa ao largo dessas discussões no período analisado.

Nos três jornais são perceptíveis a importância do Dia Internacional contra a Homofobia, 17 de maio (data em que a homossexualidade foi retirada da Classificação Estatística Internacional de Doenças e Problemas Relacionados com a Saúde - CID) e do Dia Mundial de Combate à aids, 1 de dezembro, para a elaboração de pautas.

As tendências da cobertura jornalística que identificamos nos anos 2010 apontam para uma condição da cobertura jornalística distinta daquela feita pela Folha no início dos 1980 e nos parece explicável por, pelo menos, três fatores:

1) a consolidação de conhecimentos sobre o vírus e as dinâmicas da aids, com a consequente descoberta dos medicamentos que compõem o coquetel. Ao mesmo tempo, contradições entre narrativas que mantêm alguns resquícios dos equívocos médicos e científicos dos anos iniciais da síndrome, não raro de alto teor homofóbico, de difusão do terror e de posturas moralistas, e narrativas que adotam os conhecimentos recentes da ciência e da medicina como parte de posturas que alertam para os preconceitos e para a inaceitabilidade de controles biopolíticos sobre os corpos;

2) como consequência do que indicamos no item anterior, as questões culturais e comportamentais perdem em relevância para pautas que tratam das descobertas em torno da aids e do HIV, predominando preocupações médicas e científicas. Essa mudança implicou em menor recorrência a pessoas e instituições identificadas com os movimentos LGBTI e/ou de defesa dos direitos humanos como agentes ouvidos para qualificar informações jornalísticas. Por outro lado, médicas e médicos especialistas, principalmente epidemiologistas, pesquisadoras e pesquisadores e representantes de governos e de agências internacionais implicadas no tratamento e prevenção da aids e do HIV ganham relevo nas narrativas jornalísticas. O combate à homofobia e sua indicação como componente de vulnerabilização à aids e ao HIV aparecem nos jornais especialmente a partir de artigos de representantes das agências internacionais ligadas à Organização das Nações Unidas e à Organização Mundial da Saúde, e em menor quantidade, por meio de artigos de representantes do governo brasileiro;

3) nas datas comemorativas governos e agências internacionais responsáveis por políticas relativas à aids e ao HIV constituem os agentes decisivos para pautas. Assim, próximo ao Dia Internacional contra a Homofobia, temos dados estatísticos sobre mortes e outras formas de violências físicas e simbólicas contra pessoas LGBTI ao redor do mundo, com denúncias de homofobia institucionalizada e lista de países que a promove, bem como alertas sobre a necessidade de criminalizar a homofobia. O Grupo Gay da Bahia é sempre destacado, com seus dados estatísticos sobre mortes de LGBTI no Brasil, assim como a Associação Internacional de Gays e Lésbicas, com dados estatísticos sobre a homofobia no mundo, com suas consequências. Por volta do Dia Mundial de Combate à aids, os jornais são pautados pela divulgação dos dados epidemiológicos produzidos pelo Ministério da Saúde e por dados vindos das agências internacionais. Fica evidente a influência do Ministério da Saúde nas pautas jornalísticas sobre os números relativos à aids e ao HIV nas já referidas narrativas acerca do aumento de incidência entre jovens gays, com a ressalva de que o tom de terrorismo e moralismo fica por conta dos jornais. Em 2010, a apresentação dos dados epidemiológicos veio com destaque aos jovens gays, seguindo a estratégia de a cada ano chamar atenção para determinada população que tenha apresentado aumento de notificações. 


\section{Considerações finais}

A história dos movimentos LGBTI no Brasil está distante das perspectivas lineares e de consensos quanto às suas motivações políticas, comportamentais, culturais e ideológicas. Ela tem sido marcada por rupturas, vaidades pessoais, dissensos diversos - marcas de quaisquer experiências sociais coletivas -, mas acima de tudo, pelo desejo de aprimoramento das estratégias de lutas, com a incorporação, ao longo dos anos, de pautas específicas de cada ingrediente que compõe a 'sopa de letrinhas'. Nessa curta trajetória de menos de meio século, o Brasil saiu de uma ditadura civil-militar para a tentativa de uma experiência duradoura de democracia, agora posta à prova por um governo com todos os indícios de autoritarismo conservador, alimentado por fundamentalismos religiosos e ideológicos que representam desafios sem dúvida complexos para as populações LGBTI, alvo prioritário de ataques e eleitas como inimigas a combater. Momento para repensar estratégias, promover alianças e superar diferenças ligadas mais a vaidades do que a efetivas necessidades de reivindicar especificidades. $O$ aprendizado político tem sido frutífero nessa curta trajetória, marcada por idas e vindas políticas, assim como pelos desafios impostos pela aids e pelo HIV.

Nesse sentido, na contramão da lógica da aids enquanto um marcador do outro, o movimento homossexual, até por se ver diante dos contornos das definições epidemiológicas dos equivocados grupos de risco, teve que enfrentar a epidemia física e simbólica como algo que lhe pertencia. Isso não ocorreu sem ausências de conflitos ou de uma série de contradições, como a relutância de setores do movimento que recusaram aderir a ações de enfrentamento à epidemia por temerem o acirramento da associação da doença à homossexualidade, da ambivalência nas relações de aproximação e distanciamento entre o movimento com o aparato do Estado ou mesmo nas definições dos modos de funcionamento de ONGs e coletivos para controle da aids que relutavam em estabelecer modelos de ação mais assistencialistas ou politizados. Em que pesem essas disputas e o reavivamento das fobias sociais, o movimento LGBTI foi atravessado e constituído, a partir de meados dos anos 1980, no bojo desses processos, afetado pelas dimensões práticas, culturais e políticas da aids enquanto uma construção social, como observamos na visibilidade positiva e/ ou negativa conferidas ao movimento e aos sujeitos que o constituíam em função da ampliação da epidemia.

A reportagem da revista Época e outras situações de reprodução de estereótipos ilustram como o preconceito em relação ao vírus e às pessoas LGBTI é anacrônico, não diz de uma época ou de valores morais superados, mas reaparece em algumas circunstâncias e ainda pode ganhar relevo em contextos políticos, sociais e culturais conservadores. Nesse sentido, lembramos que não há direito que seja eternamente garantido, como o acesso à terapia antirretroviral gratuita e universal pelo SUS ou a possibilidade de defesa jurídica em caso de situações de discriminação contra quem vive com o vírus. Assim, há nos desafios impostos ao movimento de combate à disseminação do HIV e ao próprio movimento LGBTI a manutenção de políticas públicas de saúde historicamente constituídas que visam garantir a diminuição de novas infecções e o sucesso no tratamento antirretroviral, assim como a contínua luta no campo da visibilidade e do reconhecimento social. Dificilmente esses enfrentamentos podem se dar sem a consideração efetiva de marcadores sociais de diferença como de gênero, sexualidade, classe social, raça etc., tão caros na compreensão das camadas de vulnerabilidade que constituem o cenário do HIV e da aids contemporaneamente, assim como nos relevos que configuram as múltiplas e plurais vivências LGBTI.

A trajetória dos movimentos LGBTI, assim como as questões relativas à aids e ao HIV, com suas múltiplas consequências, têm sido objeto de diversas polêmicas e contraditórias coberturas jornalísticas, assim como de experiências de uma genericamente nomeada 'imprensa homossexual', geralmente com publicações de curta duração. As relações do jornalismo com os movimentos LGBTI estão longe de harmoniosas, como indica Leila Míccolis, pois os conflitos surgem já no nascedouro e com críticas vindas precisamente do jornal 'Lampião da Esquina', que em dado momento passou a detratar o incipiente movimento homossexual, ação 
que a poeta e ensaísta - além de militante - considera como uma das causas para o rápido declínio do movimento logo em seus primeiros anos de atuação ${ }^{6}$.

Relativamente à aids e ao HIV, o jornalismo tem se apresentado ambíguo e contraditório desde os primeiros casos vindos a público, particularmente na fase das manchetes sensacionalistas no estilo 'câncer gay' e 'peste rosa'. No entanto, é impossível pensar estratégias de visibilidade às questões no entorno da aids e do HIV sem o auxílio da imprensa, restando a necessidade de permanente cobrança de compromissos éticos que evitem abordagens estereotipadas e preconceituosas que, aliás, dependem também das posições de diversos agentes ouvidos na produção das narrativas jornalísticas. A destacar também que, a partir das experiências de youtubers e de canais na internet, há probabilidade de diminuição da importância do jornalismo na difusão de informações sobre os movimentos LGBTI, com suas pautas de reivindicações, o mesmo valendo para novas estratégias de visibilidade e difusão de informações sobre as experiências de viver com o HIV. Como vantagem inegável, a internet oferece a possibilidade de passar adiante informações sem a necessidade da intermediação tipicamente jornalística.

Retomando Caetano Velosoํㅜ citado em epígrafe que abre este artigo, os genocidas em potencial, "de batina, de gravata ou de avental" pairam como eterna ameaça. Eles estão mais na ativa do que nunca em nossos tempos sombrios, exigindo forças que transformem as ameaças de trevas em um multicolorido arco-íris.

\section{Referências}

1. Veloso C. Black or white/Americano. In: Veloso C. Circuladô Vivo [CD]. Rio de Janeiro; PolyGram; 1992. 2 CDs.

2. Green JN, Quinalha R, Caetano M, Fernandes M, organizadores. História do movimento LGBT no Brasil. São Paulo: Alameda; 2018.

3. Trevisan JS. Devassos no paraíso: a homossexualidade no Brasil, da colônia à atualidade. Rio de Janeiro: Record; 2000.

4. Sampaio JV, Germano IMP. Políticas Públicas e crítica queer: algumas questões sobre identidade LGBT. Psicol. Soc. 2014;26(2):290-300. doi: http://dx.doi.org/10.1590/S0102-71822014000200006.

5. Macrae E. A construção da igualdade: identidade sexual e política no Brasil da abertura. Campinas: Unicamp; 1990.

6. Facchini R. Sopa de letrinhas? Movimento homossexual e produção de identidades coletivas nos anos 90. Rio de Janeiro: Garamond; 2005.

7. Daniel $H$, Míccolis L. Jacarés e lobisomens: dois ensaios sobre a homossexualidade. Rio de Janeiro: Achiamé; 1983.

8. Green JN. Revolucionário e : a vida extraordinária de Herbert Daniel, pioneiro na luta pela democracia, diversidade e inclusão. Rio de Janeiro: Civilização Brasileira; 2018.

9. $\quad$ Daniel H. Vida antes da morte/Life before death. 3 ed. Rio de Janeiro: Abia; 2018.

10. Daniel H, Parker R. Aids, a terceira epidemia: ensaios e tentativas. 2 ed. Rio de Janeiro: Abia; 2018.

11. Camargo Júnior KR. As ciências da Aids e a Aids das ciências: o discurso médico e a construção da Aids. Rio de Janeiro: Relume Dumará; 1994.

12. Fausto Neto A. Comunicação e mídia impressa: estudos sobre a Aids. São Paulo: Hacker Editores; 1999.

13. Pollak M. Os homossexuais e a Aids: sociologia de uma epidemia. São Paulo: Estação Liberdade; 1988.

14. Sedgwick EK. Epistemology of the closet. Berkeley, University of Califórnia Press; 1990.

15. Mbembe A. Necrpolítica. São Paulo: N-1 Edições; 2018.

16. Galvão J. Aids no Brasil: agenda de construção de uma epidemia. Rio de Janeiro/São Paulo: ABIA/ Editora 34; 2000.

17. Parker R. A Aids no Brasil: a construção de uma epidemia. In: A construção da solidariedade: Aids, sexualidade e política no Brasil. Rio de Janeiro: Relume-Dumará; 1994. 
18. Giddens A. Sociologia. Porto Alegre: Artmed; 2005.

19. Carvalho CA. Jornalismo, homofobia e relações de gênero. Curitiba: Appris; 2012.

20. Colling L, organizador. Stonewall 40 + o que no Brasil?. Salvador: EDUFBA; 2011.

21. Thomaz D. A outra pílula azul. Revista Época 2018 abril; p.34.

22. Teixeira FB, Paulino DB, Raimondi GA, Crovato CAA, Prado MAM. Entre o segredo e a possibilidade de cuidado: (re)pensando os silêncios em torno das narrativas das travestis sobre HIV/Aids. Sex., Salud Soc. 2018;29:373-388. doi: http://dx.doi.org/10.1590/1984-6487.sess.2018.29.17.a.

23. Carvalho CA. Visibilidades mediadas nas narrativas jornalísticas - a cobertura da Aids pela Folha de S.Paulo de 1983 a 1987. São Paulo: Annablume; 2009.

24. Carvalho CA. Narrativa jornalística e memória: a cobertura noticiosa dos 30 anos de aparição pública da Aids. Líbero. 2012;15:105-118.

25. Carvalho CA. Afetar e ser afetado pelo acontecimento: coberturas jornalísticas da Aids e impactos sociais. Intercom. 2015;38:253-272. doi: http://dx.doi.org/10.1590/1809-58442015213. 